\title{
Comparing the effect of including omega-3 to treatment regimen in elderly patients with ulcerative colitis with placebo: A randomized clinical trial
}

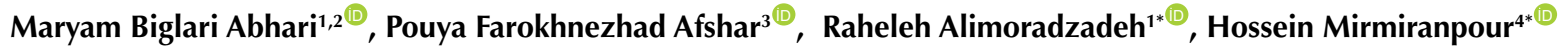 \\ 'Firoozabadi clinical Research Development Unit, Iran University of Medical Sciences, Tehran, Iran \\ ${ }^{2}$ Preventive Medicine and Public Health Research Center, Iran University of Medical Sciences, Tehran, Iran \\ ${ }^{3}$ School of Behavioral Sciences and Mental Health, Tehran Institute of psychiatry, Iran University of Medical Sciences, Tehran, Iran \\ ${ }^{4}$ Endocrinology and Metabolism Research Center, School of Medicine, Tehran University of Medical of Sciences, Tehran, Iran
}

\section{*Correspondence to \\ Raheleh Alimoradzadeh, Email: \\ Alimoradzadeh.r@iums.ac.ir and Hossein Mirmiranpour, \\ Email: h_mirmiranpoor@ \\ yahoo.com}

Received 16 Oct. 2019 Accepted 3 Dec. 2019

Published online 28 Dec. 2019

Keywords: Omega-3, Treatment regimen, Elderly patients, Ulcerative colitis, Reactive oxygen species

\section{Abstract}

Introduction: Ulcerative colitis is a chronic inflammatory disease which reduces the quality of life and patients productivity. People in different ages could be affected since its complications such as colon perforation and cancer are common. Oxidative stress is reported to create an imbalance between reactive oxygen species (ROS) and antioxidant defense systems which occurs in inflammatory tissues and predisposing malignant tumors.

Objectives: We aimed to evaluate the effects of omega- 3 on inflammatory, antioxidant, and oxidative markers of patients with ulcerative colitis.

Patients and Methods: Seventy elderly patients with ulcerative colitis referring to Rasoul-e-Akram hospital (Iran University of Medical Sciences) with mild or moderate phase of the disease were investigated. Patients were undergoing their protocol treatment. Patients were randomly assigned to the block randomization assignment, including 35 patients (routine + omega-3) or control (routine + placebo). Based on a researcher-made checklist, the severity of the disease, as well as the oxidant, antioxidant, and inflammatory factors of the patients were determined before and after 2 months of treatment. Finally, the changes in these factors were compared between groups.

Results: Among the 70 participants, 35 were in the control and 35 in the intervention group. All subjects were present during the whole period of the study, so the attrition rate was $0 \%$. No significant difference was observed between the mean of $\mathrm{BMI}$ (body mass index) as $\mathrm{kg} / \mathrm{m} 2$, waist circumference $(\mathrm{cm})$, systolic pressure $(\mathrm{mm} \mathrm{Hg})$, and diastolic pressure $(\mathrm{mm} \mathrm{Hg})$ in both groups before and after the intervention. The measure of optimal changes in serum levels of MDA (malondialdehyde oxidant), AGEs (advanced glycation end-products), oxidized LDL (oxidized low density lipoprotein), TNF- $\alpha$ (tumor necrosis factor-alpha) and the improvement of antioxidant catalase copper markers were significantly higher in the intervention group, compared to the control one. Conclusion: Administration of omega-3 as an auxiliary component in the treatment of patients significantly reduced the levels of inflammatory and oxidative markers and a significant increase in antioxidant markers in the serum and improved blood pressure in patients with ulcerative colitis.

Trial registration: The trial protocol was approved in the Thai Clinical Trials Registry (identifier: TCTR20191215001: http://www.clinicaltrials.in.th/index.php?tp=regtrials\&menu=trialsearch\&smenu=fulltex t\&task=search\&task2=view1\&id=5567, ethical code; IR.IUMS.FMD.REC.1397.108).
Citation: Biglari Abhari M, Farokhnezhad Afshar $P$, Alimoradzadeh $\mathrm{R}$, Mirmiranpour $\mathrm{H}$. Comparing the effect of including omega-3 to treatment regimen in elderly patients with ulcerative colitis with placebo: A randomized clinical trial. Immunopathol Persa. 2020;6(1):e10. DOI:10.15171/ ipp. 2020.10

\section{Introduction}

Ulcerative colitis is a chronic debilitating inflammatory disease with distressing symptoms which reduce the quality of life and patients' productivity (1). People in different ages could be affected (2) since serious complications such as colon perforation and cancer are common. Due to chronic and recurrent trend of the disease, patients need to receive appropriate treatment and follow-up throughout their lifetime (1). The likelihood of colorectal cancer increases during 8-10 years after the onset of the first

\begin{abstract}
Key point
Administration of omega-3 as an auxiliary componen in the treatment of ulcerative colitis significantly reduced the levels of inflammatory and oxidative markers and showed a significant increase in antioxidant markers in the serum of our patients.
\end{abstract}

symptoms (3) while more than 14250 new cases are detected in the world each year (4). Therefore, therapeutic and preventive interventions should be prioritized. The etiology of the disease and the mechanism

Copyright $\odot 2020$ The Author(s); Published by Nickan Research Institute. This is an open-access article distributed under the terms of the Creative Commons Attribution License (http://creativecommons.org/licenses/by/4.0), which permits unrestricted use, distribution, and reproduction in any medium, provided the original work is properly cited. 
of cancer development are not well-known. It seems that factors such as the involvement of susceptible genes, defects of epithelial dams, lack of regulation of immune responses (5), and its resulting inflammation and ultimately environmental factors play a significant role in its pathogenesis (6). Accordingly, the role of cytokines has been prominent, and the concentrations of cytokines such as IL(interleukin)-4, IL-10 (interleukin 10), IL-6, tumor necrosis factor (TNF) in the serum and intestinal tissue increase during the recurrence and activity of the disease (3,7-11). It seems that oxidative stress accounts for the trigger and activating inflammatory responses (2,3,12-14).

Oxidative stress is reported to create an imbalance between reactive oxygen species (ROS) and antioxidant defense systems which occurs in inflammatory tissues and predisposing malignant tumors (13).

Measuring the plasma level of oxidative factors in ulcerative colitis can indicate an oxidative stress which is more invasive and more accessible than the colon tissue samples, and can help assess the severity of the disease (14). Increased levels of oxidative stress markers such as AOPP (advanced oxidation protein products) have been reported in ulcerative colitis activity (13).

On the other hand, the reduction of serum levels of antioxidant activity markers such as glutathione-stransferase and ferric reducing ability of plasma [FRAP $\left.\left(\mathrm{mmol} \mathrm{Fe}{ }^{2+} / \mathrm{g}\right)\right]$ indicates ulcerative colitis disease activity (15).

In general, researchers believe that antioxidant compounds may be used to treat ulcerative colitis and prevent cancer $(12,16)$.

Several studies have examined the anti-inflammatory and antioxidant effects of fish oil and omega-3 (17-20), while some of which have indicated the beneficial effects of these compounds in controlling the inflammatory colitis $(21,22)$. In addition, there are beneficial protective effects in the animal model $(23,24)$. In some cases, omega- 3 may be more effective than some monoclonal-anti-TNF reagents $(25,26)$.

\section{Objectives}

The present study aimed to evaluate the effects of omega-3 on inflammatory, antioxidant, and oxidative markers of the patients with ulcerative colitis.

\section{Patients and Methods}

Study design and participants

In this study, 70 elderly patients with ulcerative colitis referring to Rasoul-e-Akram hospital (Iran University of Medical Sciences) with mild or moderate phase of the disease which undergoing treatment, were randomly assigned to the block randomization assignment including 35 patients (routine + omega-3) or control (routine + placebo) (Figure 1). Based on a researcher-made checklist, the severity of the disease, and the oxidant, antioxidant, and inflammatory factors of the patients were determined (before the treatment) and after 2 months of treatment. Finally, the changes in these factors were compared in groups.

The patients and researchers were blinded while randomization was conducted by the clinical clerk. The type of selected approach was recorded for each patient in a packed envelope, which distributed the admittance receiver without informing the envelope content until the sample size was completed. All elderly people over 60 years old with mild to moderate ulcerative colitis which were diagnosed with colonoscopy while colon biopsy included in the present study. The elderly patients

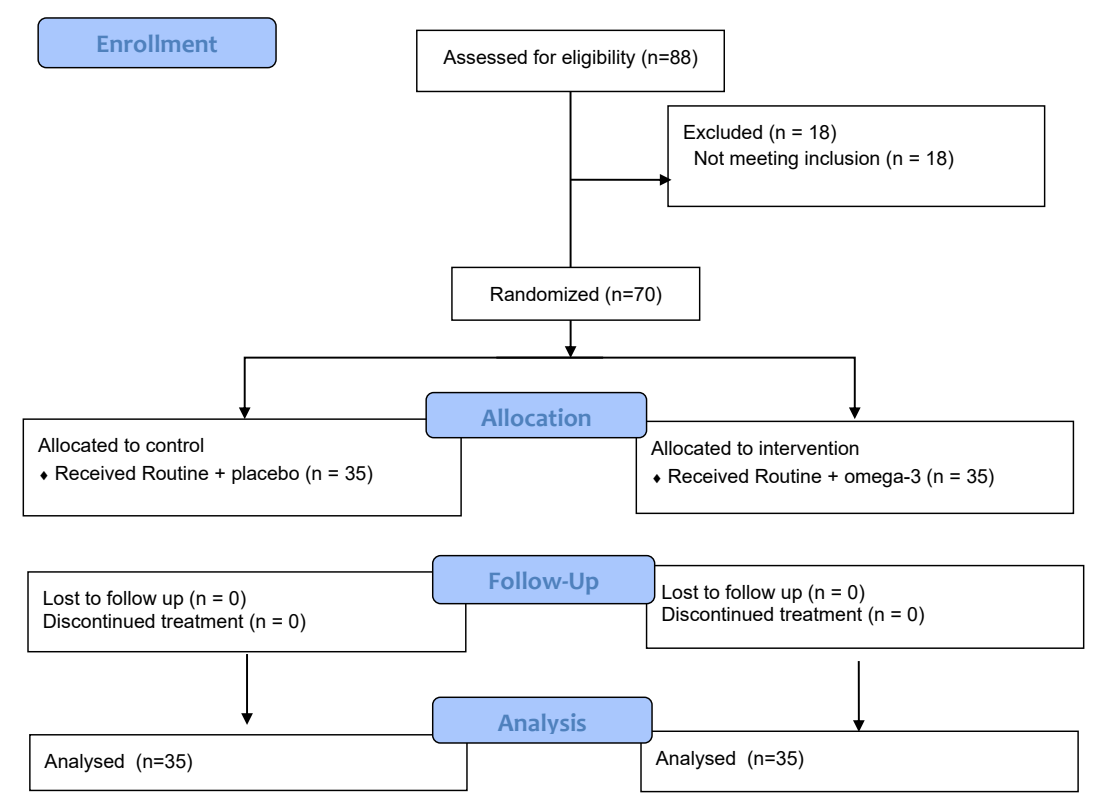

Figure 1. CONSORT diagram showing the flow of participants through each stage of a randomized trial. 
with indeterminate colitis, intestine functional disorder associated with inflammatory bowel disease (IBD) and bacterial infection simultaneously with IBD were excluded.

Elderly patients as the intervention group received 4.3 $\mathrm{g}(4800 \mathrm{mg}$ ) of omega-3 (4 capsules of $1200 \mathrm{mg}$ ) per day for two months (10). However, the elderly patients in the control group received placebo (starch) as $500 \mathrm{mg}$ capsules and 4 capsules per day for two months and were observed the same with the intervention group.

\section{Measurements}

The serum of patients was first sampled in both the control and experimental groups before starting the treatment and administrating omega-3. Then, it was conducted for the second time, two months after administrating omega-3. Based on the sterilization conditions, $10 \mathrm{~mL}$ of blood was taken from the cubital vein of each case, among which $5 \mathrm{ml}$ of the blood was sucked into the glass tube and circulated for 25 minutes at $2500 \mathrm{~g}$ centrifugation for 10 minutes. Then, $2.5 \mathrm{~mL}$ of the serum was removed from the blood and kept at $-70^{\circ} \mathrm{C}$. In addition, $5 \mathrm{~mL}$ of residual was poured into a plastic tube containing $200 \mu \mathrm{L}$ of EDTA (ethylenediaminetetraacetic acid) and accordingly $3.5 \mathrm{~mL}$ of plasma was removed and stored at $-70^{\circ} \mathrm{C}$ after 10 -minute centrifugation at $2500 \mathrm{~g}$. Then the serum and plasma of patients were used to measure oxidant, antioxidant, and inflammatory factors when needed.

In the next stage, the activity level of the antioxidant catalase, glutathione peroxidase, and superoxide dismutase was measured by colorimetric method. Then, malondialdehyde oxidant [MDA $(\mu \mathrm{m} / \mathrm{L})]$ was measured by colorimetric method while oxidized LDL [Ox-LDL $(\mathrm{mg} / \mathrm{dL})]$ was measured by ELISA (enzyme-linked immunosorbent assay) method (27).

To measure the advanced glycation end-products [AGEs (unit/milliliter)] as oxidative index, the serum sample was diluted 1: 50 by PBS (phosphate buffered saline) with $\mathrm{pH} 7.4$, followed by a fluorescence intensity of 440 $\mathrm{nm}$ in wavelength and the excitation wavelength was 350 $\mathrm{nm}$. The fluorescence intensity was expressed in terms of the percentage of fluorescence emission (28). Further, the AOPP as an oxidant index was determined by using a spectrophotometer device based on the Kalousova method. In addition, $200 \mu \mathrm{L}$ serum diluted with PBS (pH 7.4) of 1 to $5,200 \mu \mathrm{L}$ of chloramine $\mathrm{T}$ at a concentration range of $0-100 \mu \mathrm{mol} / \mathrm{L}$ for calibration, and $200 \mu \mathrm{L}$ of PBS as a blanch in each of the wells were poured into the plate. Then, $10 \mu \mathrm{L}$ of KI with $1.6 \mathrm{M}$ concentration and $20 \mu \mathrm{L}$ of acetic acid were added to each of these wells. Further, absorbance measurement at $340 \mathrm{~nm}$ and expression of AOPP concentration were made in terms of chloramine units $(\mu \mathrm{mol} / \mathrm{L})(29)$.

To measure FRAP ( $\left.\mu \mathrm{mol} \mathrm{Fe} \mathrm{Fe}^{2+} / \mathrm{mg}\right), 750 \mu \mathrm{L}$ FRAP reagent was added to $25 \mu \mathrm{L}$ of plasma in the test tubes. In addition, their absorbance at $593 \mathrm{~nm}$ was read using a spectrophotometer. The FRAP reagent was obtained by mixing a $300 \mathrm{mM}$ acetate buffer with the $\mathrm{pH}$ of 6.3, 2, 4, 6-trisipyridyl-s-triazine (TPTZ) of $10 \mathrm{mM}$ in $40 \mathrm{mM}$ chloride acid, and chloride ferric 6A $20 \mathrm{mM}$ which is available in the ratio of 10.1.1. In this method, the antioxidant agents in the test sample resulted in reducing the pyridine Estherasein complex (TPTZ-Fe3+) in the form of ferrous (TPTZ-Fe2+), which was blue in acidic medium, and had an optical absorption in the wavelength of $593 \mathrm{~nm}$. The above reaction speed had a linear relationship with the regenerative power of the sample (30). Inflammatory factors included TNF- $\alpha$, IL1 $\alpha$, IL1 $\beta$, IL2 and IL6. Demographic and anthropometric variables in the checklist including age, fender, BMI (body mass index; $\mathrm{kg} / \mathrm{m}^{2}$ ), waist circumference $(\mathrm{cm})$, hip circumference $(\mathrm{cm})$, and systolic and diastolic blood pressure (mm Hg) were measured. Anthropometric and main variables as inflammatory factors included AGEs, AOPP, malondialdehyde (MDA), Ox-LDL as oxidant and FRAP, glutathione peroxidase, superoxide dismutase and catalase as antioxidant and interleukin 1 alpha (IL-1 $\alpha$ ), IL1 $\beta$, IL2, IL6, and TNF- $\alpha$ were measured in the pre and post-treatment period of omega- 3 administration by the relevant methods.

\section{Ethical issues}

The research followed the Tenets of the Declaration of Helsinki. To keeping ethical principles, names of the patients were not pointed in the checklists. Ethics approval was also obtained from Iran University of Medical Sciences and ethics committee (IR.IUMS.FMD.REC.1397.108). Patients' information was fully preserved. Before conducting the study, all of the possible effects and complications of the intervention were fully explained to the patients, and then the sampling was conducted with satisfaction. In addition, the patients received a consent form. The trial protocol was approved in the Thai Clinical Trials Registry (identifier: TCTR20191215001; http://www.clinicaltrials. in.th/index.php?tp=regtrials\&menu=trialsearch\&smenu= fulltext\&task=search\&task2=view1\&id=5567).

\section{Statistical analysis}

The data analysis was performed using SPSS, version 20.0 (SPSS Inc., Chicago, IL, USA). In order to compare effects of treatment regimens, we used independent $t$ test for comparison between groups and paired t-test to compare variables before and after the intervention.

\section{Results}

Among the 70 participants, 35 were in the control and 35 in the intervention group. All subjects were present during the study, since the attrition ratio was $0 \%$. The mean age in the control and intervention group was 69.71 and 69.94 years, respectively. In other words, no significant difference was observed.

As shown in Table 1, no significant difference was observed between the mean of BMI, waist circumference, 
Table 1. Characteristics of participants before the intervention

\begin{tabular}{llll}
\hline Variable & & Mean $(\mathrm{SD})$ & P value \\
\hline \multirow{2}{*}{ Age (year) } & Control & $69.71(5.07)$ & \multirow{2}{*}{0.982} \\
& Intervention & $69.74(5.53)$ & \\
\hline \multirow{2}{*}{ BMI $\left(\mathrm{kg} / \mathrm{m}^{2}\right)$} & Control & $29.86(4.23)$ & \multirow{2}{*}{0.363} \\
& Intervention & $29.02(3.33)$ & \\
\multirow{2}{*}{ Waist circumference $(\mathrm{cm})$} & Control & $101.74(10.25)$ & \multirow{2}{*}{0.243} \\
& Intervention & $99.06(8.75)$ & \\
\multirow{2}{*}{ Systolic BP $(\mathrm{mm} \mathrm{Hg})$} & Control & $124.00(9.76)$ & \multirow{2}{*}{0.543} \\
& Intervention & $125.43(9.8)$ & \\
\multirow{2}{*}{ Diastolic BP $(\mathrm{mm} \mathrm{Hg})$} & Control & $71.1(7.18)$ & \multirow{2}{*}{0.783} \\
\hline
\end{tabular}

systolic pressure, and diastolic pressure in both groups before and after intervention.

Table 2 indicates the serum level of the above items before and after intervention in each group. As seen, the serum levels of all oxidative, antioxidant and inflammatory markers, and diastolic and systolic pressure changed significantly after the study in the intervention group, while only serum levels of AGE, MDA, Ox-LDL, catalase, superoxide dismutase and TNF- $\alpha$ altered in the control group. In fact, the favorite changes in the serum levels of MDA, AGE, Ox-LDL, TNF- $\alpha$ and the improvement of antioxidant catalase activity were significantly higher in the intervention group, compared to the control subjects (Table 3).

Figure 2A-F illustrates the comparison of the changes in these markers in both groups before and after the intervention.

\section{Discussion}

Based on the results, the addition of omega- 3 to the treatment regimen of patients with ulcerative colitis could reduce inflammatory factors of exacerbating the disease. In fact, omega- 3 can be used as a complementary component in the prescribed treatment, which may improve response to the treatment.

Barbosa et al concluded that the addition of omega-3 and fish oil for treating the patients with ulcerative colitis can reduce oxidative stress significantly (31).

Seidner et al indicated that addition of oral omega- 3 to the diet of patients with ulcerative colitis can increase the response to treatment and decrease their corticosteroid dose (32). Further, Meister et al observed that omega-3 may increase IL-1ra and decrease IL-1B in the inflammatory tissue and suggested the use of its rectal form (33). Hudert et al found that mice with a high level of serum omega-3 were protected against the incidence of ulcerative colitis (23). In another retrospective cohort study, John et al examined 25639 people aged between 45-75 years and identified 22 incident cases which represented that taking omega-3 EPA (eicosapentaenoic acid), docosahexaenoic acid over the age of 45 has a protective effect against ulcerative colitis (34). Furthermore, Varnalidis et al indicated that omega-3 consumption increased serum level of hemoglobin, neutrophil accumulation and activity of myeloperoxidase in the intestinal tract of the mouse, while it significantly reduced the severity of the disease (35). Grimstad et al observed that salmon consumption as a rich source of omega-3, reduced significantly serum levels of IL-6, IL-10, IL-2, IL- $1 \beta$, TNF- $\alpha$ and simple clinical colitis activity index among the patients with ulcerative colitis (36).

The prophylactic and therapeutic role of omega-3 in ulcerative colitis was also confirmed in the study by Marcon

Table 2. Blood pressure, weight and serum level of factors before and after the intervention in groups

\begin{tabular}{|c|c|c|c|c|c|c|}
\hline \multirow{2}{*}{ Variable } & \multicolumn{3}{|c|}{ Control group } & \multicolumn{3}{|c|}{ Intervention group } \\
\hline & Before & After & $P$ value & Before & After & $P$ value \\
\hline Systolic BP (mm Hg) & 124 & 124.86 & 0.083 & 127.14 & 125.43 & 0.012 \\
\hline Diastolic BP (mm Hg) & 71.71 & 72.57 & 0.083 & 74.00 & 71.14 & 0.001 \\
\hline Weight (kg) & 79.94 & 80.03 & 0.556 & 73.71 & 74.03 & 0.362 \\
\hline AGEs (unit/mL) & 70.90 & 67.39 & 0.009 & 69.04 & 63.32 & 0.007 \\
\hline $\operatorname{AOPP}(\mu \mathrm{mol} / \mathrm{L})$ & 137.037 & 134.33 & 0.629 & 131.83 & 121.10 & 0.005 \\
\hline $\mathrm{MDA}(\mu \mathrm{mol} / \mathrm{L})$ & 3.39 & 3.25 & 0.000 & 3.43 & 2.23 & 0.000 \\
\hline Ox-LDL (mg/dL) & 17.55 & 16.62 & 0.000 & 17.69 & 13.71 & 0.000 \\
\hline $\operatorname{FRAP}(\mu \mathrm{mol} \mathrm{Fe} 2+/ \mathrm{mg})$ & 1075.34 & 1137.62 & 0.265 & 993.08 & 1323.88 & 0.000 \\
\hline Catalase* (units/mL) & 2.082 & 2.325 & 0.000 & 2.002 & 2.74 & 0.000 \\
\hline Glutathione (units/mL ) & 86.98 & 86.05 & 0.121 & 85.08 & 97.53 & 0.000 \\
\hline Superoxide dismutase ${ }^{* *}($ units/mg) & 3.96 & 4.197 & 0.000 & 4.068 & 4.988 & 0.000 \\
\hline TNF- $\alpha^{* * *}$ & 11.15 & 11.05 & 0.032 & 11.41 & 10.46 & 0.000 \\
\hline IL-6 & 6.02 & 5.95 & 0.48 & 6.13 & 5.19 & 0.000 \\
\hline IL-2 & 11.65 & 11.56 & 0.276 & 11.51 & 10.61 & 0.000 \\
\hline IL-1 $\alpha$ & 11.48 & 11.39 & 0.331 & 11.54 & 10.63 & 0.000 \\
\hline IL-1 $\beta$ & 6.03 & 5.96 & 0.307 & 6.09 & 5.12 & 0.000 \\
\hline
\end{tabular}

* Unit definition: One unit of catalase will decompose $1.0 \mu$ mole of $\mathrm{H} 2 \mathrm{O} 2$ per minute at $\mathrm{pH} 7.0$ at $25^{\circ} \mathrm{C}$, while the $\mathrm{H} 2 \mathrm{O} 2$ concentration falls from $10.3 \mathrm{mM}$ to

$9.2 \mathrm{mM}$. The rate of disappearance of $\mathrm{H} 2 \mathrm{O} 2$ is followed by observing the rate of decrease in the absorbance at $240 \mathrm{~nm}$.

** Unit definition: One unit is defined as that amount of enzyme causing half the maximum inhibition of NBT reduction.

${ }^{* * *}$ Cytokine levels are given as $\mathrm{pg} / \mathrm{dL}$. 
Table 3. Comparison of factors level changes between groups

\begin{tabular}{lccc}
\hline \multirow{2}{*}{ Factor } & \multicolumn{2}{c}{ Mean of changes in serum level of factor } & \multirow{2}{*}{$\boldsymbol{P}$ value } \\
\cline { 2 - 3 } & Control group & Intervention group & \\
\hline TNF- $\alpha(\mathrm{pg} / \mathrm{dL})$ & -10.2571 & -94.5143 & 0.000 \\
$\begin{array}{l}\text { Superoxide } \\
\text { dismutase* }\end{array}$ & 0.2314 & 0.9200 & 0.000 \\
Catalase $(\mathrm{units} / \mathrm{mL})$ & 0.2429 & 0.7400 & 0.000 \\
\hline MDA $(\mu \mathrm{mol} / \mathrm{L})$ & -0.138 & -1.2006 & 0.000 \\
AGEs $(\mathrm{unit} / \mathrm{mL})$ & -3.51 & -5.71 & 0.353 \\
Ox-LDL $(\mathrm{mg} / \mathrm{dL})$ & -0.93 & -3.98 & 0.000 \\
\hline
\end{tabular}

et al (37). Additionally, Reddy et al concluded that a hybrid diet with hydroxytyrosol plus oleic acid and omega- 3 has a major therapeutic benefit in the active phase of ulcerative colitis disease and may induce remission (38).

Some review studies, for example the study of Chapkin et al confirmed the beneficial effects of omega-3, which was considered to be effective in treating ulcerative colitis disease and the prevention of progression to colon cancer (39). Similar results were found in some other studies (40-43). Likewise, Barbalho et al showed the benefices of Omega- 3 in treatment of IBDs (44). Similarly, Limketkai et al indicated that omega-3 as an effective antiinflammatory formulation should be supplemented with nutrition for patients with ulcerative colitis. In addition, it could reduce the severity of the disease by decreasing serum cytokines (45). However, the results of the present study were inconsistent with those of some other studies.
De Ley et al reported no evidence supporting the role of omega-3 in remission of ulcerative colitis disease (46). Turner et al found no evidence that Omega-3 can be used to maintain ulcerative colitis disease in the remission phase (47). Cabré et al, failed to demonstrate the positive effects of omega-3s, suggesting that larger size trials and more precise control are needed (48). Besides, Yates et al concluded that omega-3 compound is not very effective in some diseases such as asthma and IBD, despite the very beneficial effects of omega- 3 in chronic inflammatory diseases (49). Furthermore, vascular changes were observed in ulcerative colitis disease. Despite the fact that systolic and diastolic blood pressure in these patients was not significantly different from the normal population, an increasing in aortic stiffness was observed, which may be associated with increased blood pressure in the longterm (50). In the present study, the effects of omega- 3 on reducing blood pressure were confirmed in patients with ulcerative colitis. Despite the beneficial effects of omega-3 in the present study, it is recommended to be conducted larger RCTs with more samples and prospective cohorts with precise design in order to obtain more accurate and reliable results to recommend omega-3, according to its therapeutic and preventative effects in ulcerative colitis.

\section{Conclusion}

Administration of omega-3 as an auxiliary component in the treatment of patients significantly reduced the levels of inflammatory and oxidative markers and showed a
(A)

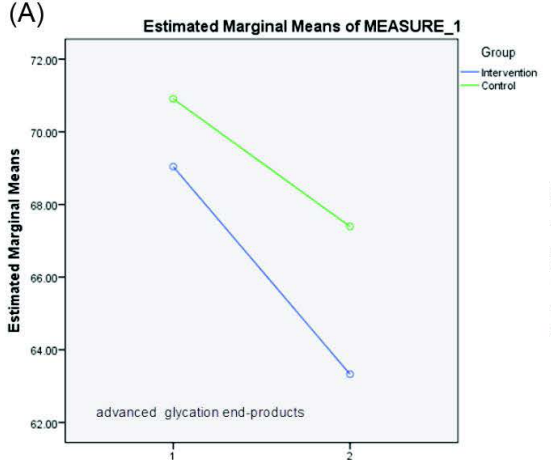

(D)

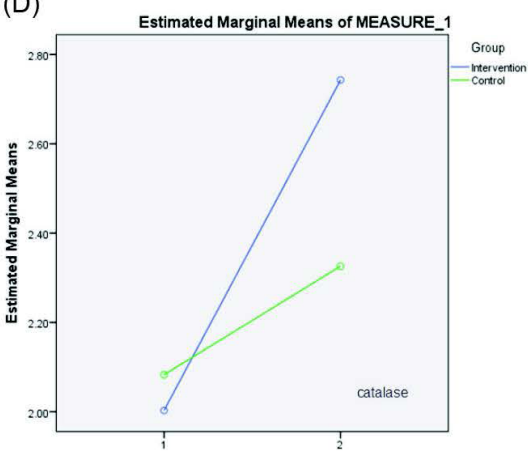

(B)

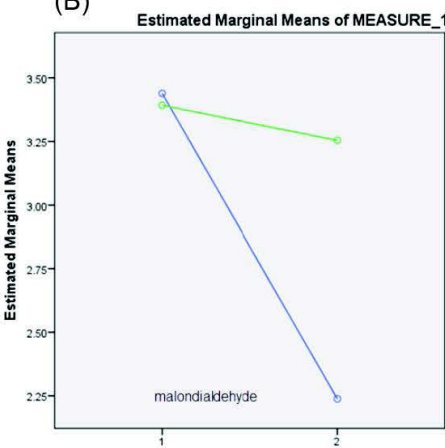

(E)

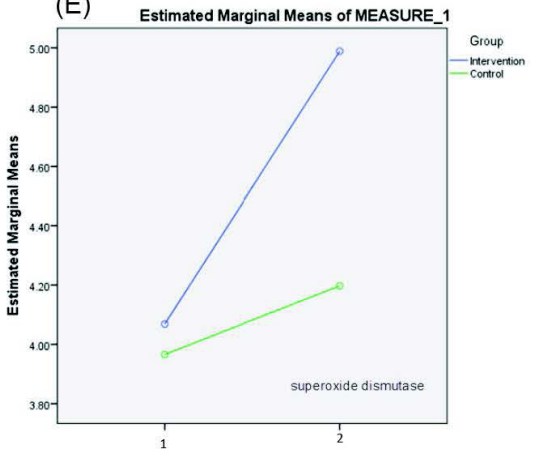

(C)
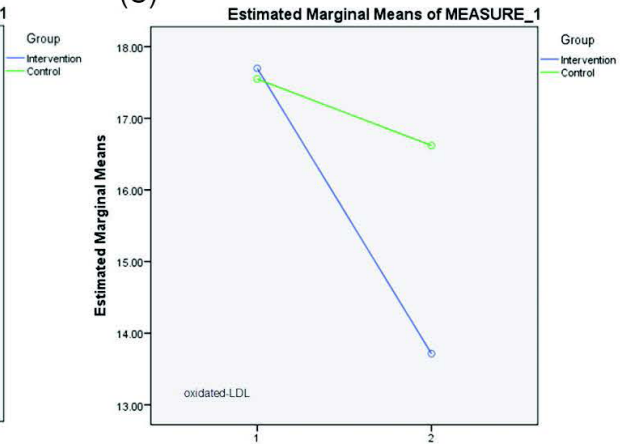

(F)

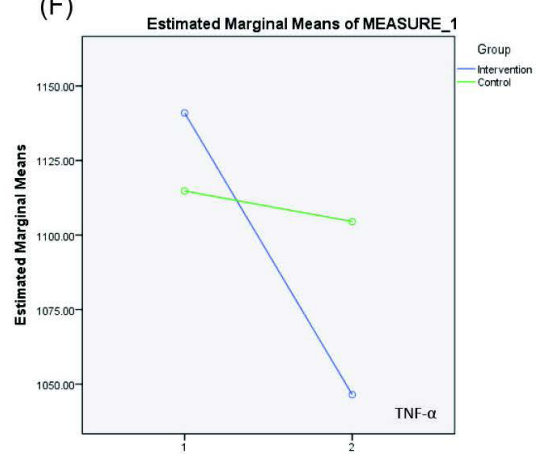

Figure 2. Comparison of (A) AGE, (B) MDA, (C) Ox-LDL, (D) catalase, (E) superoxide dismutase and (F) TNF- $\alpha$ level changes in groups. Abbreviations: AGE, Advanced glycation end- product; MDA, malondialdehyde. 
significant increase in antioxidant markers in the serum of our patients. This treatment improved blood pressure in our patients too.

\section{Limitations of the study}

Our study had two major limitations containing; 1. Small sample size: the conducted study was considered as a pilot intervention to estimate an initial effect size. Hence we can estimate the main sample size using the results for a larger trial in the future. 2. Shortness of the following duration. To assess long-term effects of treatments and estimate recurrence rate changes, we should follow the patients for a longer period.

\section{Authors' contribution}

All authors had the same contribution with active participation in all steps of the study. MBA and RA searched the literature and prepared the primary draft. MBA conducted the final edition. MBA performed statistical analysis. HM, PFA and RA have done the practical paraclinical parts of study, intervention and data collection. All authors wrote and signed the final paper.

Conflicts of interest

There was no conflict of interests for authors.

Ethical considerations

Ethical issues including plagiarism and double publication have been completely observed by the authors.

\section{Funding/Support}

No funder supported the current research.

\section{References}

1. Fumery M, Singh S, Dulai PS, Gower-Rousseau C, PeyrinBiroulet L, Sandborn WJ. Natural history of adult ulcerative colitis in population-based cohorts: a systematic review. Clin Gastroenterol Hepatol. 2018;16:343-56. doi: 10.1016/J. CGH.2017.06.016.

2. Rana SV, Sharma S, Prasad KK, Sinha SK, Singh K. Role of oxidative stress \& antioxidant defence in ulcerative colitis patients from north India. Indian J Med Res. 2014;139:568-71.

3. Rana SV, Sharma S, Kaur J, Prasad KK, Sinha SK, Kochhar R, et al. Relationship of cytokines, oxidative stress and GI motility with bacterial overgrowth in ulcerative colitis patients. J Crohns Colitis. 2014;8:859-65. doi: 10.1016/j.crohns.2014.01.007.

4. Macrae FA. Colorectal cancer: Epidemiology, risk factors, and protective factors. Uptodate. 2016. https://www.uptodate. com/contents/colorectal-cancer-epidemiology-risk-factorsand-protective-factors.

5. Roose L, D'cunja J, Biedermann L. Ulcerative colitis. Praxis (Bern 1994). 2016;105:607-15. doi: 10.1024/1661-8157/ a002358.

6. Ungaro R, Mehandru S, Allen PB, Peyrin-Biroulet L, Colombel JF. Ulcerative colitis. Lancet. 2017;389:1756-1770. doi: 10.1016/S0140-6736(16)32126-2.

7. Moldoveanu AC, Diculescu M, Braticevici CF. Cytokines in inflammatory bowel disease. Rom J Intern Med. 2015;53:11827. doi: 10.155/rjim-2015-0016

8. Balmus IM, Ciobica A, Trifan A, Stanciu C. The Implications of Oxidative Stress and Antioxidant Therapies in Inflammatory Bowel Disease: Clinical Aspects and Animal Models. Saudi J Gastroenterol. 2016;22:3-17. doi: 10.4103/13193767.173753.

9. Macaluso FS, Renna S, Orlando A, Cottone M. The biologics of ulcerative colitis. Expert Opin Biol Ther. 2017;17:175-184. doi: 10.1080/14712598.2017.1271871.

10. Pugliese D, Felice C, Papa A, Gasbarrini A, Rapaccini GL, Guidi L, et al. Anti TNF- $\alpha$ therapy for ulcerative colitis: current status and prospects for the future. Expert Rev Clin Immunol. 2017;13:223-233. doi: 10.1080/1744666X.2017.1243468.

11. Müzes G, Molnár B, Tulassay Z, Sipos F. Changes of the cytokine profile in inflammatory bowel diseases in inflammatory bowel diseases. World J Gastroenterol. 2012;18:5848-61. doi: 10.3748/wjg.v18.i41.5848.

12. Pereira C, Grácio D, Teixeira JP, Magro F. Oxidative Stress and DNA Damage: Implications in Inflammatory Bowel Disease. Inflamm Bowel Dis. 2015;21:2403-17. doi: 10.1097/ MIB.0000000000000506.

13. Roessner A, Kuester D, Malfertheiner P, Schneider-Stock R. Oxidative stress in ulcerative colitis-associated carcinogenesis. Pathol Res Pract. 2008;204:511-24. doi: 10.1016/j. prp.2008.04.011.

14. Sies $\mathrm{H}$, Berndt $\mathrm{C}$, Jones DP. Oxidative Stress. Annu Rev Biochem. 2017:86:715-48. doi: 10.1146/annurevbiochem-061516-045037.

15. Baskol M, Baskol G, Kocer D, Ozbakir O, Yucesoy M. Advanced oxidation protein products: a novel marker of oxidative stress in ulcerative colitis. J Clin Gastroenterol. 2008;42:687-91.

16. Alagozlu H, Gorgul A, Bilgihan A, Tuncer C, Unal S. Increased plasma levels of advanced oxidation protein products (AOPP) as a marker for oxidative stress in patients with active ulcerative colitis. Clin Res Hepatol Gastroenterol. 2013;37:80-5. doi: 10.1016/j.clinre.2012.03.034

17. Krzystek-Korpacka M, Neubauer K, Berdowska I, Boehm D, Zielinski B, Petryszyn P, et al. Enhanced Formation of Advanced Oxidation Protein Products in IBD. Inflamm Bowel Dis. 2008;14:794-802. doi: 10.1002/ibd.20383.

18. Wang Z, Li S, Cao Y, Tian X, Zeng R, Liao DF, et al. Oxidative Stress and Carbonyl Lesions in Ulcerative Colitis and Associated Colorectal Cancer. Oxid Med Cell Longev. 2016;2016:9875298. doi: 10.1155/2016/9875298.

19. Tian T, Wang Z, Zhang J. Pathomechanisms of Oxidative Stress in Inflammatory Bowel Disease and Potential Antioxidant Therapies. Oxid Med Cell Longev. 2017;2017:4535194. doi: 10.1155/2017/4535194.

20. Lorente-Cebrián S, Costa AG, Navas-Carretero S, Zabala M, Laiglesia LM, Martínez JA, et al. An update on the role of omega-3 fatty acids on inflammatory and degenerative diseases. J Physiol Biochem. 2015;71:341-349. doi: 10.1007/ s13105-015-0395-y.

21. Matsunaga H, Hokari R, Kurihara C, Okada Y, Takebayashi K, Okudaira K, et al. Omega-3 fatty acids exacerbate DSS-induced colitis through decreased adiponectin in colonic subepithelial myofibroblasts. Inflamm Bowel Dis. 2008;14:1348-57. doi: 10.1002/ibd.20491.

22. Nieto N, Torres MI, Ríos A, Gil A. Dietary polyunsaturated fatty acids improve histological and biochemical alterations in rats with experimental ulcerative colitis. J Nutr. 2002;132:9-11. doi: 10.1093/jn/132.1.11.

23. Hudert CA, Weylandt KH, Lu Y, Wang J, Hong S, Dignass $\mathrm{A}$, et al. Transgenic mice rich in endogenous omega-3 fatty acids are protected from colitis. Proc Natl Acad Sci U S A. 2006;103:11276-81. doi: 10.1073/pnas.0601280103.

24. Bento AF, Claudino RF, Dutra RC, Marcon R, Calixto JB. Omega-3 fatty acid-derived mediators 17(R)-hydroxy docosahexaenoic acid, aspirin-triggered resolvin D1 and resolvin D2 prevent experimental colitis in mice. J Immunol. 2011;187:1957-69. doi: 10.4049/jimmunol.1101305.

25. de Barros KV, de Abreu GG, Xavier RA, Martinez CA, Ribeiro $\mathrm{ML}$, Gambero A, et al. Effects of a high fat or a balanced 
omega 3/omega 6 diet on cytokines levels and DNA damage in experimental colitis. Nutrition. 2011;27:221-6. doi: 10.1016/j. nut.2009.11.014.

26. Robles HV, Ochoa KF, Nava P, Olivares AS, Shibayama M, Schnoor M. Analyzing Beneficial Effects of Nutritional Supplements on Intestinal Epithelial Barrier Functions During Experimental Colitis. J Vis Exp. 2017:e55095. doi: 10.3791/55095.

27. Bevan RJ, Durand MF, Hickenbotham PT, Kitas GD, Patel PR, Podmore ID, et al. Validation of a novel ELISA for measurement of MDA-LDL in human plasma. Free Radic Biol Med. 2003;35:517-27. doi: 10.1016/S0891-5849(03)00359-9.

28. de la Maza MP, Garrido F, Escalante N, Leiva L, Barrera G, Schnitzler S, et al. Fluorescent advanced glycation end-products (ages) detected by spectro-photofluorimetry, as a screening tool to detect diabetic microvascular complications. J Diabetes Mellitus. 2012;2:221-226. doi: 10.4236/jdm.2012.22035.

29. Taylor EL, Armstrong KR, Perrett D, Hattersley AT, Winyard PG. Optimisation of an advanced oxidation protein products assay: its application to studies of oxidative stress in diabetes mellitus. Oxid Med Cell Longev. 2015;2015:496271. doi: 10.1155/2015/496271.

30. Benzie IF, Devaki M. The ferric reducing/antioxidant power (FRAP) assay for non-enzymatic antioxidant capacity: concepts, procedures, limitations and applications. Measurement of antioxidant activity \& capacity: recent trends and applications. New York: Wiley; 2018:77-106.

31. Barbosa DS, Cecchini R, El Kadri MZ, Rodríguez MA, Burini RC, Dichi I. Decreased oxidative stress in patients with ulcerative colitis supplemented with fish oil $\omega-3$ fatty acids. Nutrition. 2003;19:837-42. doi: 10.1016/S0899-9007(03)00162-X.

32. Seidner DL, Lashner BA, Brzezinski A, Banks PL, Goldblum J, Fiocchi $C$, et al. An oral supplement enriched with fish oil, soluble fiber, and antioxidants for corticosteroid sparing in ulcerative colitis: a randomized, controlled trial. Clin Gastroenterol Hepatol. 2005;3:358-69. doi: 10.1016/s15423565(04)00672-x.

33. Meister D, Ghosh S. Effect of fish oil enriched enteral diet on inflammatory bowel disease tissues in organ culture: Differential effects on ulcerative colitis and Crohn's disease. World J Gastroenterol. 2005;11:7466-7472. doi: 10.3748/wjg. v11.i47.7466.

34. John S, Luben R, Shrestha SS, Welch A, Khaw KT, Hart AR. Dietary n-3 polyunsaturated fatty acids and the aetiology of ulcerative colitis: a UK prospective cohort study. Eur J Gastroenterol Hepatol. 2010;22:602-6. doi: 10.1097/ MEG.0b013e3283352d05.

35. Varnalidis I, Ioannidis O, Karamanavi E, Ampas Z, Poutahidis T, Taitzoglou I, et al. Omega 3 fatty acids supplementation has an ameliorative effect in experimental ulcerative colitis despite increased colonic neutrophil infiltration. Rev Esp Enferm Dig. 2011;103:511-8. doi: 10.4321/s1130-01082011001000003.

36. Grimstad T, Berge RK, Bohov P, Skorve J, Gøransson L, Omdal R, et al. Salmon diet in patients with active ulcerative colitis reduced the simple clinical colitis activity index and increased the anti-inflammatory fatty acid index - a pilot study. Scand J Clin Lab Invest. 2011;71:68-73. doi: 10.3109/00365513.2010.542484.

37. Marcon R, Bento AF, Dutra RC, Bicca MA, Leite DF, Calixto JB. Maresin 1, a Proresolving Lipid Mediator Derived from Omega-3 Polyunsaturated Fatty Acids, Exerts Protective Actions in Murine Models of Colitis. J Immunol. 2013;191:4288-98. doi: 10.4049/jimmunol.1202743.

38. Reddy KV, Naidu KA. Oleic acid, hydroxytyrosol and n-3 fatty acids collectively modulate colitis through reduction of oxidative stress and IL-8 synthesis; in vitro and in vivo studies. Int Immunopharmacol. 2016;35:29-42. doi: 10.1016/j. intimp.2016.03.019.

39. Chapkin RS, McMurray DN, Lupton JR. Colon cancer, fatty acids and anti-inflammatory compounds. Curr Opin Gastroenterol. 2007;23:48-54. doi: 10.1097/MOG.0b013e32801145d7.

40. Rajendran N, Kumar D. Role of diet in the management of inflammatory bowel disease. World J Gastroenterol. 2010;16:1442-1448. doi: 10.3748/wjg.v16.i12.1442.

41. Hur SJ, Kang SH, Jung HS, Kim SC, Jeon HS, Kim IH, et al. Review of natural products actions on cytokines in inflammatory bowel disease. Nutr Res. 2012;32:801-16. doi: 10.1016/j.nutres.2012.09.013.

42. Sung MK, Park MY. Nutritional modulators of ulcerative colitis: Clinical efficacies and mechanistic view. World J Gastroenterol. 2013;19:994-1004. doi: 10.3748/wjg.v19.i7.994.

43. Farrukh A, Mayberry JF. Is there a role for fish oil in inflammatory bowel disease? World J Clin Cases. 2014;2: 250-252. doi: 10.12998/wjcc.v2.i7.250.

44. Barbalho SM, de Alvares Goulart R, Quesada K, Bechara MD, de Carvalho AD. Inflammatory bowel disease: can omega-3 fatty acids really help? Ann Gastroenterol. 2016;29:37-3.

45. Limketkai BN, Wolf A, Parian AM. Nutritional Interventions in the Patient with Inflammatory Bowel Disease. Gastroenterol Clin North Am. 2018;47:155-177. doi: 10.1016/j. gtc.2017.09.007.

46. De Ley M, de Vos R, Hommes DW, Stokkers PC. Fish oil for induction of remission in ulcerative colitis. Cochrane Database Syst Rev. 2007:CD005986.

47. Turner D, Steinhart AH, Griffiths AM. Omega 3 fatty acids (fish oil) for maintenance of remission in ulcerative colitis. Cochrane Database Syst Rev. 2007:CD006443.

48. Cabré E, Mañosa M, Gassull MA. Omega-3 fatty acids and inflammatory bowel diseases-a systematic review. Br J Nutr. 2012;107:S240-52. doi: 10.1017/S0007114512001626.

49. Yates CM, Calder PC, Rainger GE. Pharmacology and therapeutics of omega-3 polyunsaturated fatty acids in chronic inflammatory disease. Pharmacol Ther. 2014;141:272-82. doi: 10.1016/j.pharmthera.2013.10.010.

50. Nemes A, Gavallér H, Nagy F, Náfrády J, Wittmann T, Forster T. Increased aortic stiffness in ulcerative colitis. Cent Eur J Med. 2014;9:40-4. 